\title{
Instituciones de
}

\section{microfinanciación en el desarrollo de mercados financieros}

\section{Eva Terberger}

\section{Profesora}

Departamento de Economía,

Universidad de Heidelberg,

Alemania

eva.terberger@awi.uni-heidelberg.de
En las últimas dos décadas la microfinanciación ha sido considerada un importante instrumento para luchar contra la pobreza, ya que al facilitar el acceso de los hogares pobres a servicios financieros formales puede contribuir a mejorar sus condiciones de vida y promover el desarrollo económico. Además, muchos consideran que es eficiente, dado que algunas instituciones creadas por la conversión de organizaciones no gubernamentales en microbancos (upscaling) han mostrado que es posible dar servicio financiero a esos hogares y a la vez cubrir los costos, e incluso, lograr una moderada rentabilidad. Sin embargo, en varios estudios recientes se percibe cierto escepticismo frente a este enfoque, ya que las instituciones de microfinanciación rentables son más bien excepcionales. Para reproducir en mayor escala esos pocos excelentes resultados se precisan innovaciones institucionales. Este artículo pretende hacer una primera incursión en las potencialidades de dos alternativas relativamente nuevas: la creación de departamentos de microfinanciación en bancos con fines de lucro existentes (downscaling), o la fundación de bancos de nuevo cuño. 


\title{
Motivación: ¿pueden hacerse realidad las potencialidades de las microfinanzas por la vía de crear instituciones adecuadas?
}

\author{
Cerca de mil millones de personas en todo el mundo pertenecen a familias \\ cuyo ingreso per cápita es inferior a un dólar diario. Los encargados de \\ formular políticas y los especialistas que han estado intentando mejorar las \\ condiciones de vida de esas personas enfrentan obstáculos enormes... \\ En medio de fracasos desalentadores, se están cifrando muchas \\ expectativas en un conjunto de instituciones financieras poco comunes que \\ están prosperando en lugares muy apartados del planeta, especialmente en \\ Bangladesh, Bolivia e Indonesia. Lo que se espera es mitigar una parte \\ importante de la pobreza y transformar profundamente las estructuras \\ económicas y sociales, proporcionando servicios financieros a los hogares \\ de bajos ingresos. Estas instituciones, unidas bajo el pabellón de las \\ microfinanzas, comparten la voluntad de prestar servicios a clientes \\ excluidos del sector bancario formal... (Morduch, 1999, p. 1569).
}

Difícilmente pueda ilustrarse de manera más vívida el atisbo de esperanza despertado por las potencialidades de las microfinanzas que en los párrafos arriba citados, con los cuales se inicia el artículo de fondo de Morduch sobre este tema publicado en el Journal of Economic Literature de diciembre de 1999. Ese trabajo bien merece ser considerado como un hito en la bibliografía sobre la microfinanciación, por dos motivos:

- En primer lugar, durante años tanto los especialistas en desarrollo como los políticos habían prestado considerable atención al tema de las microfinanzas. Sin embargo, hasta la aparición del artículo mencionado el tema sólo había concitado el interés de un círculo bastante hermético de científicos. El logro de Morduch fue presentarlo a una amplia gama de estudiosos de la economía.

- En segundo lugar, en ese estudio se señala claramente que, a pesar de que durante más de dos décadas los donantes han dedicado y siguen dedicando millones de dólares de ayuda a la creación de instituciones microfinancieras, '...las enormes potencialidades de la microfinanciación aún no son realidad y las afirmaciones más audaces en ese sentido no resisten un análisis riguroso" ${ }^{1}$ (Morduch, 1999, p. 1571).

\footnotetext{
${ }^{1}$ En este artículo, las citas que aparecen entre comillas simples han sido traducidas del original.
}

¿De qué estamos hablando al referirnos a las potencialidades de la microfinanciación? Hasta ahora, ¿qué esperanzas han sido defraudadas? El concepto básico de la microfinanciación es relativamente simple. Al desarrollar el mercado financiero por la vía de abrir servicios financieros formales a los hogares de bajos ingresos y, lo que es más importante, a los pequeños empresarios y los microempresarios, se da a estas personas la posibilidad de ayudarse a sí mismas. Ellas pueden superar la pobreza reduciendo las fluctuaciones de sus patrones de consumo y obteniendo préstamos para inversiones que les permitan mejorar sus negocios y, de esta manera, aumentar los ingresos de la familia, contribuir a la creación de puestos de trabajo y fomentar tanto el desarrollo de un sector de pequeñas empresas muy dinámico como el crecimiento económico en general. Además, y éste parece ser el rasgo más atrayente de la microfinanciación, dar acceso a los servicios financieros para combatir la pobreza promete ser un procedimiento relativamente eficiente, es decir, eficaz en función de los costos. Se cree que tras una etapa inicial de desarrollo institucional subsidiado, las instituciones de microfinanciación pueden alcanzar la sostenibilidad financiera. ${ }^{2}$ Quienes promueven las microfinanzas están convencidos de que es posible organizar servicios financieros para los pobres

\footnotetext{
${ }^{2}$ Véase Krahnen y Schmidt (1994).
} 
que cubran los costos, permitiendo que las instituciones que brindan tales servicios sobrevivan en el mercado sin un apoyo financiero permanente y que hasta logren una rentabilidad moderada. Si esto realmente se pudiera hacer, la microfinanciación se convertiría en una solución en la que todos saldrían ganando, ya que beneficiaría tanto a la clientela pobre como a los propietarios de las instituciones microfinancieras. Sin necesidad del combustible adicional representado por los subsidios permanentes, las fuerzas comerciales del mercado financiero podrían continuar la lucha contra la pobreza como un móvil perpetuo.

La evidencia examinada en el trabajo de Morduch genera cierto escepticismo sobre la viabilidad real de la microfinanciación. En lo que se refiere a sus efectos sobre la pobreza, existen muy pocos estudios empíricos en los que realmente se analice si existen sesgos en los datos relativos a los clientes de las instituciones microfinancieras. ${ }^{3}$ En consecuencia, más allá de algunos estudios de casos ilustrativos, hay escasa información empírica que demuestre que la microfinanciación ha tenido un impacto positivo en las condiciones de vida de los clientes y la creación de empleo. Asimismo, parece haber buenas razones para poner en duda que la microfinanciación, al cabo de un período limitado de desarrollo institucional subvencionado, pueda convertirse en un arma de costo cero para combatir la pobreza. Si bien muchas de las instituciones dedicadas a esta actividad pueden exhibir muy buenos resultados en la evaluación del riesgo crediticio de microclientes que supuestamente carecían de las condiciones necesarias para incorporarse al sistema bancario, 'rara vez las tasas elevadas de devolución de los créditos se han traducido en beneficios para los prestadores, como sugiere la publicidad' (Morduch, 1999, p. 1571). El sueño de que las instituciones de microfinanciación puedan convertirse en una solución en la que todos ganan y que la comercialización se transforme en una fuerza impulsora de la lucha contra la pobreza parece estar muy alejado de la realidad. De los varios miles de entidades de microfinanciación existentes en el mundo, sólo un puñado de instituciones paradigmáticas están cumpliendo con su doble misión de servir a los pobres y al mismo tiempo ser sostenibles en términos financieros.

A la luz de estos datos, que invitan a la reflexión, Morduch concluye que es preciso ser más realista frente a las potencialidades de las microfinanzas, pero sin

${ }^{3}$ Véase Khandker, Samad y Khan (1998); también Morduch (2000). descartarlas. La idea de promover la autoayuda por medio del acceso a servicios financieros es demasiado atractiva como para dejarla de lado, aunque más no sea porque la historia de la microfinanciación ha demostrado que es posible lograr mejoras importantes si se aprende de los errores cometidos. Los resultados de la primera generación de proyectos de microfinanciación, que surgieron en el decenio de 1970 y consistían en créditos subsidiados a manera de "regalo" a los pobres que no reunían las condiciones necesarias para ingresar al sistema bancario, fueron un fracaso estrepitoso. ${ }^{4}$ Se perdieron cuantiosas sumas porque muy pocos de esos préstamos fueron devueltos. ${ }^{5}$ Además, como los créditos subsidiados resultaban atractivos para todos, en muchos casos el dinero ni siquiera llegaba a miembros de los grupos destinatarios. ${ }^{6}$ Como resultado de las enseñanzas dejadas por estos fracasos surgió un nuevo enfoque de la microfinanciación, que apuntaba a no seguir confundiendo préstamos con obsequios. Los "regalos" financieros no ayudaban a desarrollar los mecanismos del mercado financiero, sino que más bien habían contribuido a distorsionarlos. Por consiguiente, se generó un enfoque de la microfinanciación orientado al mercado: los hogares de bajos ingresos que no tenían acceso a los bancos fueron vistos como clientes capaces de devolver los préstamos si la institución microfinanciera hacía hincapié en una disciplina de pago; además, las tasas de interés de los microcréditos no debían ser menores que las de mercado para los créditos de mayor cuantía, con el fin de no concitar el interés de personas ajenas al grupo destinatario. A partir de ese momento, la microfinanciación dejó de considerarse un instrumento de transferencia de riqueza a los pobres para convertirse más bien en un mecanismo de desarrollo de los mercados financieros.

Fue esta primera ola de innovación institucional, centrada en la tecnología del crédito y en una relación institución-cliente, lo que condujo al logro de altas tasas de reembolso por las actuales instituciones microfinancieras. Este éxito, que al menos en algunos casos notorios de instituciones de esta índole les permitió recuperar los costos, obtener beneficios y registrarse como entidades financieras formales (algo considerado imposible algunos años atrás), dio pie al sueño

\footnotetext{
4 Véase Vogel (1984).

5 'El más importante elemento de subsidio al crédito no eran las tasas artificialmente bajas, sino el hecho de que prestatarios avispados (e influyentes) tenían muchas posibilidades de evadir por completo el pago de los préstamos' (Krahnen y Schmidt, 1994, p. 20). ${ }^{6}$ Véase Adams, Graham y Von Pischke, 1984.
} 
de la solución "beneficiosa para todos". Si este sueño aún no se ha hecho realidad en gran escala, Morduch y otros $^{7}$ aconsejan mejorar la configuración institucional de las entidades microfinancieras. Se deberá 'volver a analizar con detenimiento las estructuras de gestión y el diseño de los mecanismos a fin de reducir los costos, manteniendo al mismo tiempo la amplitud de la cobertura. No será sencillo lograrlo, pero resulta difícil imaginar logros significativos si no se encara una segunda gran ola de innovación' (Morduch, 1999, p. 1609).

En realidad, en los últimos años se ha innovado considerablemente en este campo, esta vez haciendo hincapié en el marco institucional de las entidades y en su estructura de propiedad y de gestión. En su gran mayoría, las instituciones existentes sobre cuyo análisis Morduch basó su evaluación todavía conservan la estructura de ONG o bien iniciaron sus actividades como tales. Las de mayor éxito quizás hayan modificado su estructura jurídica durante el proceso de conversión en un banco formal especializado en microfinanzas (upscaling), como lo hicieron las instituciones paradigmáticas del movimiento de microfinanciación en Bolivia: el BancoSol y la Casa los Andes. ${ }^{8}$ Inspirados por tal éxito y por el sueño de comercializar microcréditos, los donantes comenzaron a experimentar con soluciones institucionales distintas de la conversión de ONG. Los proyectos para crear departamentos de microcréditos en instituciones financieras formales existentes (downscaling) fueron una de las innovaciones con las que se experimentó en la década de 1990. A fines de esa década, los donantes adoptaron un nuevo enfoque. En lugar de convertir a las ONG, se crearon bancos de nuevo cuño (greenfield banks), especializados en microfinanciación, pero que contaban desde un principio con licencia para operar como entidades bancarias. Se constituyeron como sociedades anónimas y sus accionistas fueron las instituciones donantes e inversionistas privados. Por lo demás, una empresa de inversiones especializada en acciones de cartera de las instituciones microfinancieras fue la que lideró el proceso de creación de esos nuevos bancos. Tales innovaciones institucionales tienen más puntos de contacto con una actividad financiera "real" que el largo proceso de convertir a las ONG - cuyo objetivo original es ayudar a los pobres- en una institución bancaria formal. Cabe preguntarse si ha comenzado finalmente la era de la microfinanciación comercial y si las innovaciones institucionales descritas pueden hacer realidad la microfinanciación a mayor escala. En las secciones siguientes se intentará responder a estos interrogantes.

La sección II incluye una clasificación de las alternativas institucionales para crear entidades de microfinanciación, a saber, la conversión de ONG, la creación de departamentos especializados dentro de bancos existentes o la creación de bancos de nuevo cuño. Esa clasificación pretende servir en cierto modo de base teórica para identificar no sólo las distintas características institucionales de estos tres enfoques, sino también para obtener los primeros indicios sobre sus ventajas y desventajas potenciales. En las secciones III y IV se proporciona información empírica sobre algunos proyectos para crear departamentos de microfinanciación en bancos existentes o de fundar bancos de nuevo cuño, a fin de transmitir una primera impresión sobre sus posibilidades. Por último, en la sección V se formulan algunas conclusiones preliminares.

\section{Incorporar la microfinanciación en un banco comercial, estrategia opuesta a convertir una ONG en microbanco}

Convencer a un banco comercial tradicional de que ofrezca microcréditos por su propia cuenta, sin que el

\footnotetext{
${ }^{7}$ Como Banerjee (2002), y Hulme y Mosley (1998).

8 Véase Rhyne (2001).
}

gobierno haya puesto en vigor normas para esa actividad, solía considerarse una iniciativa totalmente inútil. Después de todo, la idea de las microfinanzas como instrumento de desarrollo económico había surgido porque esos bancos no tenían ningún interés en prestar servicios a clientes de bajos ingresos. Hasta los exper- 
tos que conocían bien los éxitos de la microfinanciación orientada al mercado en el decenio de 1980 y principios de la década de 1990 eran más bien escépticos frente a proyectos en ese sentido. Hulme y Mosley (1996, p. 157), quienes publicaron los resultados de sus investigaciones sobre la creación de instituciones de microfinanciación en 1996, llegaron a la conclusión siguiente: 'La observación más significativa debe ser que las instituciones sin fines de lucro (incluidas las del sector público y las organizaciones no gubernamentales) parecen tener ventajas comparativas frente a las instituciones con fines de lucro para prestar servicios financieros formales a los pobres'. Esta aseveración se basa en tres argumentos centrales:

- El primero es de carácter empírico: prácticamente ninguna de las instituciones encuestadas era una empresa dedicada exclusivamente a las actividades con fines de lucro. '...la única empresa incluida en nuestro estudio que prestaba ese tipo de servicios, y que había alcanzado una situación de madurez relativa, era BancoSol. Se había originado en PRODEM, una organización no gubernamental' (Hulme y Mosley, 1996, p. 157).

- Los otros dos argumentos tienen un carácter más bien teórico, vinculado con la estructura de gestión de las instituciones. El primero de ellos es que 'las empresas privadas sencillamente no están dispuestas a aportar capital de riesgo para prestar servicios experimentales a prestatarios (y ahorristas) de bajos ingresos... El segundo tiene que ver con la premisa errónea de que algunas características de la gestión del sector privado esenciales para la prestación eficaz de servicios financieros (determinación de costos y precios, recuperación de costos, promoción en el personal de una mentalidad orientada a obtener resultados) sólo se encuentran en las empresas con fines de lucro' (Hulme y Mosley, 1996, pp. 157 y 158).

Sin embargo, ninguno de los tres argumentos es en realidad convincente. En primer lugar, el que no se haya intentado hacer algo no significa que no pueda hacerse. En segundo lugar, quizás las empresas privadas no estén dispuestas a invertir capital de riesgo en la esfera de la microfinanciación, pero también es cierto que los donantes no esperan que lo hagan. Una de las características de los proyectos de crear departamentos de microcréditos en bancos formales es que una institución donante subsidie los costos de la puesta en marcha de tales departamentos. En tercer lugar, los autores citados sin duda tienen razón al creer que las técnicas de gestión empleadas en el sector privado pueden aplicarse en las organizaciones sin fines de lucro. La conversión de ONG en microbancos supone precisamente eso y es lo que explica el éxito del enfoque de mercado de la microfinanciación. Sin embargo, quizás un criterio tanto o más eficaz para crear estas instituciones microfinancieras sea aprovechar el incentivo "natural" de las empresas con fines de lucro a cubrir los costos, en lugar de transformar una institución sin fines de lucro, concebida para ayudar a un determinado grupo destinatario, en una organización que respete las limitaciones presupuestarias y los requisitos de eficiencia económica.

No obstante, los argumentos de Hulme y Mosley dan la clave para comprender la diferencia fundamental entre los enfoques alternativos de desarrollo institucional (cuadro 1). Dichos autores establecen la comparación entre las instituciones de microfinanciación con fines de lucro y aquellas sin fines de lucro, en lugar de comparar el enfoque basado en la conversión de ONG en microbancos (lo que se conoce como upscaling) con el enfoque basado en la creación de departamentos de microfinanzas en bancos existentes (conocido como downscaling). Al hacer alusión al tamaño de la institución o a una modificación ascendente o descendente de escala, las expresiones upscaling y downscaling, surgidas en la bibliografía sobre microfinanciación para caracterizar a dos estrategias opuestas en materia de desarrollo institucional son, en el mejor de los casos, engañosas. Lo que interesa en la construcción de tales instituciones no es tanto su tamaño. La diferencia fundamental radica en la estructura de propiedad y de gestión característica de la institución que se utiliza como punto de partida. En los proyectos de conversión de ONG en microbancos por lo general se parte de una ONG pequeña perteneciente al sector financiero informal o semiformal. En cambio, para la creación de departamentos de microfinanciación en bancos formales generalmente se busca una entidad más grande, ya registrada como entidad financiera formal. No obstante, en este último caso las condiciones esenciales son los objetivos comerciales y la estructura de propiedad del banco comercial. Para que haya un auténtico proyecto de downscaling, la institución pertinente debe ser un banco con fines de lucro del sector privado. Si se trata de un banco estatal, sus características serán similares a las de una ONG, por más que sea formal y de gran tamaño. Por el contrario, un prestamista privado, aunque sea pequeño e informal, comparte las características principales de los bancos comerciales privados. Visto de esta manera, la creación de un banco de nuevo cuño en realidad no es una 
Alternativas institucionales para las actividades de microfinanciación

\begin{tabular}{|c|c|c|c|c|}
\hline & & Sin fines de lucro & $?$ & Con fines de lucro \\
\hline $\begin{array}{l}\text { Institución } \\
\text { grande } \\
\downarrow\end{array}$ & $\begin{array}{l}\text { Instituciones } \\
\text { formales }\end{array}$ & $\begin{array}{l}\text { Banco estatal que lleva a } \\
\text { cabo políticas sectoriales }\end{array}$ & & \multirow{2}{*}{$\begin{array}{c}\text { Banco de propiedad privada } \\
\Omega \\
\Omega \\
\text { Creación de un departamento } \\
\text { de microfinanciación en un } \\
\text { banco formal } \\
\text { (downscaling) }\end{array}$} \\
\hline \multirow{2}{*}{$\begin{array}{l}\downarrow \\
\downarrow\end{array}$} & $\begin{array}{l}\text { Institución financiera } \\
\text { formal que presta } \\
\text { servicios a un grupo } \\
\text { destinatario }\end{array}$ & $\begin{array}{c}\text { Conversión de una ONG } \\
\text { en microbanco } \\
\text { (upscaling) } \\
\hat{\imath}\end{array}$ & $\begin{array}{l}\text { Banco de nuevo cuño } \\
\text { (greenfield bank) }\end{array}$ & \\
\hline & Semiformal & $\begin{array}{c}\hat{\varphi} \\
\mathrm{ONG}\end{array}$ & & \\
\hline Pequeña & Informal & Fondos de iglesia & & Prestamista \\
\hline
\end{tabular}

Fuente: Elaboración propia.

alternativa adicional. ${ }^{9}$ Más allá de que la creación de un banco nuevo permite ahorrar el tiempo que tomaría transformar una entidad existente y en cambio exige el esfuerzo de crear una institución desde cero, las características institucionales de los bancos de nuevo cuño pueden corresponder a las de instituciones con o sin fines de lucro, según cual sea su estructura de propiedad y de gestión, cosa que es preciso examinar (cuadro 1).

¿Cuáles son las diferencias más importantes en materia de estructura de propiedad y de gestión de las instituciones con o sin fines de lucro, que determinan los distintos problemas que habrá que resolver para transformarlas en instituciones de microfinanciación formales? Los prejuicios más comunes sobre las dificultades fundamentales que deberá enfrentar en su desarrollo institucional una entidad de microfinanciación para cumplir la doble función que le corresponde podrían dar los primeros indicios. Si bien una institución sin fines de lucro se dedicaría, por sus propias características, a prestar servicios a grupos pobres, es común suponer que le resultará difícil asegurar la eficiencia y realizar los esfuerzos necesarios para cubrir los costos. En contraposición, un banco privado supuestamente hará por su propia cuenta todo lo posible por asegurar la eficiencia en función de los costos y la rentabilidad. El mayor problema en materia de desarrollo institucional será convencer al banco de que preste servicios a microclientes.

Indudablemente, estas visiones son demasiado simplificadas. Para dar un solo ejemplo, aunque impor-

${ }^{9}$ Véase Baydas, Graham y Valenzuela, 1997. tante, puede decirse que tanto las instituciones de microfinanciación sin fines de lucro como los bancos con fines de lucro generalmente son dirigidos por administradores designados. Éstos podrían estar utilizando (indebidamente) la institución para lograr ciertos objetivos personales en lugar de dedicarse a satisfacer las necesidades del grupo destinatario o maximizar las utilidades. En consecuencia, no se puede dar por sentado que en una organización sin fines de lucro los fondos se utilizarán exclusivamente en favor del grupo destinatario, ni que la eficiencia en función de los costos sea la característica fundamental de una institución bancaria con fines de lucro. No obstante, los prejuicios más comunes no carecen totalmente de fundamento. De hecho, el principal desafío para el diseño de una estructura de gestión de una institución sin fines de lucro - trátese de una ONG o de un banco estatal- es establecer restricciones presupuestarias estrictas que le impidan perder dinero. Las mayores dificultades para establecer restricciones presupuestarias estrictas en las instituciones sin fines de lucro derivan de la estructura de la propiedad y del control: si se dona capital a una institución o se diluye su estructura de propiedad, como ocurre con frecuencia en los bancos estatales, no habrá un propietario que tenga interés personal en ejercer los derechos de control y que al mismo tiempo deba responder por los resultados (financieros) positivos o negativos de la institución (cuadro 2). En tal sentido, no hay duda de que las empresas privadas poseen una ventaja. Los propietarios no sólo tienen un incentivo para multiplicar el valor de sus acciones, ejercitando sus derechos de control, sino que tales empresas enfrentan el riesgo de insolvencia si pierden su capital (un riesgo que también obliga a los administradores designados 
CUADRO 2

Los desafíos del desarrollo institucional: instituciones con o sin fines de lucro

\begin{tabular}{|c|c|c|}
\hline & Sin fines de lucro & Con fines de lucro \\
\hline Sostenibilidad & Mecanismo "trasplantado" & Mecanismo "natural" \\
\hline Cobertura de los costos & $\begin{array}{l}\text { Riesgo de insolvencia si se interrumpe la } \\
\text { corriente de donaciones }\end{array}$ & $\begin{array}{l}\text { Riesgo de insolvencia porque los fondos de los } \\
\text { propietarios son limitados }\end{array}$ \\
\hline Eficiencia & $\begin{array}{l}\text { Prevención de la laxitud organizativa mediante } \\
\text { la imitación de las técnicas de gestión de las } \\
\text { instituciones con fines de lucro o el control } \\
\text { ejercido por los donantes }\end{array}$ & $\begin{array}{l}\text { Técnicas de gestión de las instituciones con } \\
\text { fines de lucro; competencia; gestión realizada o } \\
\text { controlada por el propietario }\end{array}$ \\
\hline Orientación al grupo destinatario & $\begin{array}{l}\text { Control ejercido por los donantes para evitar } \\
\text { que la administración abuse de la institución } \\
\text { para su propio provecho }\end{array}$ & $\begin{array}{l}\text { Control ejercido por los donantes para evitar } \\
\text { que los propietarios usen los subsidios en } \\
\text { actividades más lucrativas ajenas a las } \\
\text { necesidades del grupo destinatario }\end{array}$ \\
\hline \multicolumn{3}{|l|}{ Subsidios } \\
\hline Temporales & $\begin{array}{l}\text { Para cubrir las pérdidas hasta que la institución } \\
\text { pueda solventar los costos y conservar el } \\
\text { capital }\end{array}$ & $\begin{array}{l}\text { Para lograr que la actividad en beneficio del } \\
\text { grupo destinatario cubra los costos (incluidos } \\
\text { los costos de oportunidad del capital) }\end{array}$ \\
\hline Por un plazo indefinido & $\begin{array}{l}\text { Equivalentes a la rentabilidad del capital en una } \\
\text { inversión alternativa }\end{array}$ & \\
\hline Control ejercido por los donantes & $\begin{array}{l}\text { Por un período indefinido o hasta que se haga } \\
\text { la transición a una empresa con fines de lucro }\end{array}$ & $\begin{array}{l}\text { Hasta que las actividades en beneficio del grupo } \\
\text { destinatario sean tan rentables como otras } \\
\text { inversiones }\end{array}$ \\
\hline
\end{tabular}

Fuente: Elaboración propia.

a ser más cuidadosos). Por último, aunque no por ello menos importante, las empresas privadas generalmente deben hacer frente a la competencia, lo que restringe el margen de ineficiencia que cada una de ellas puede permitirse. Para que las organizaciones sin fines de lucro compensen sus debilidades en materia de sostenibilidad financiera, pueden imitar las técnicas de gestión de las entidades con fines de lucro, como señalan Hulme y Mosley (1996).

Aunque el "trasplante" de estas técnicas utilizadas por las instituciones con fines de lucro funcionara bastante bien (y existe un buen número de ejemplos de lo contrario), ${ }^{10}$ toma mucho tiempo y es caro, como lo demuestra el lento y prolongado proceso de conversión de ONG.

Es indudable, por lo tanto, que la estructura de propiedad de un banco con fines de lucro tiene sus ventajas respecto de la cobertura de los costos, en tan-

\footnotetext{
10 Basta pensar en todos los intentos fallidos de reformar bancos estatales.
}

to factor que garantiza la sostenibilidad de la institución. Las principales dificultades estriban (y aquí nuevamente cobran validez los prejuicios más frecuentes contra las entidades con fines de lucro) en hacer que estas instituciones se orienten al grupo destinatario. El mayor obstáculo no radica en los costos de puesta en marcha, porque las instituciones donantes están dispuestas a subsidiar los costos de ingreso. Son las perspectivas comerciales de largo plazo para servir a microclientes lo que podría hacer que entidades con fines de lucro fuesen inadecuadas como instituciones de microfinanciación.

Si bien una entidad con fines de lucro se hace sostenible tan pronto como logra cubrir los costos operacionales y financieros y evitar la descapitalización, ni el departamento de microfinanzas de un banco comercial ni una institución de microfinanciación con fines de lucro alcanzará a la vez el punto de equilibrio y la sostenibilidad. Para que la microfinanciación sea un negocio y que una institución con fines de lucro continúe en esa actividad, aunque se vayan eliminando los subsidios de los donantes y los controles 
concomitantes que ellos ejercen, no sólo debe ser rentable, sino que debe tener la misma rentabilidad que cualquier actividad que compita por los recursos limitados de un propietario de banco. Este punto de referencia, que determina la sostenibilidad de la microfinanciación en los bancos con fines de lucro, ha sido denominado en la bibliografía especializada como "la plena sostenibilidad financiera". Ella involucra, entre otras cosas, la necesidad de cubrir los costos de oportunidad del capital del propietario.

Este umbral es ineludible para las entidades con fines de lucro, pero carece de toda significación para la supervivencia de las instituciones sin fines de lucro. Se considera que una empresa privada que es parte integrante del mercado debe maximizar los beneficios y enfrentar la competencia utilizando con la mayor eficacia posible los escasos recursos de que dispone. Las instituciones sin fines de lucro no están sujetas de igual manera a estas fuerzas del mercado. Las reglas que rigen su supervivencia son otras porque, por definición, sus motivaciones no son meramente financieras. El solo hecho de que el capital de una ong provenga de donaciones la libera de la necesidad de cubrir los costos de oportunidad del capital. Mientras no genere pérdidas, puede sobrevivir casi eternamente aunque la rentabilidad del capital sea significativamente menor que la de un banco con fines de lucro.

Por ese motivo, la microfinanciación en un banco con fines de lucro es la piedra de tope para sopesar las potencialidades de la microfinanciación: si las microfinanzas pueden convertirse en una actividad realmente rentable para un banco comercial, se hace innecesario subsidiar en forma permanente a instituciones sin fines de lucro. Aun si los subsidios sólo se aportan como donación de capital, siempre será necesaria la supervisión de los donantes para evitar su mal uso por laxitud organizativa. ${ }^{11}$

Las entidades con fines de lucro cuentan con ventajas efectivas para desempeñarse como instituciones microfinancieras, siempre y cuando la microfinanciación pueda convertirse en una solución que beneficie a todas las partes interesadas en un período acotado de tiempo. Cabe preguntarse si las innovaciones en la estructura de tales instituciones - a saber, la creación de departamentos de microfinanzas en bancos con fines de lucro y la fundación de bancos de nuevo cuñorealmente suponen una experimentación con las estructuras de propiedad de las entidades con fines de lucro, y en ese caso, si ofrecen la posibilidad de materializar las expectativas puestas en la microfinanciación.

\section{III}

\section{¿Vale la pena intentar que bancos con fines de lucro incorporen departamentos de microfinanciación?}

Se han hecho intentos en tal sentido, y aunque algunos de los bancos comerciales involucrados eran estatales, existen efectivamente casos en que los bancos pertinentes eran privados y por lo tanto constituían ejemplos típicos de entidades con fines de lucro.

\section{América Latina: un ensayo en Paraguay}

El Programa Microglobal fue un proyecto bastante destacado de incorporación de departamentos de

\footnotetext{
${ }^{11}$ Este problema ha sido recurrente en la trayectoria de las cajas de ahorro de Alemania. Luego de 200 años de su fundación como instituciones estatales y municipales sin fines de lucro, siguen estando organizadas como ong sin fines de lucro.
}

microfinanciación en entidades financieras, iniciado en Paraguay en 1995 con el financiamiento del Banco Interamericano de Desarrollo (BID). ${ }^{12}$ Participaron en él ocho instituciones, de las cuales sólo una era un banco estatal. Todas las demás eran entidades financieras privadas, conocidas como "financieras", y se habían especializado hasta entonces casi exclusivamente en créditos de consumo. En todas estas instituciones se creó un departamento de microcréditos con el apoyo de donantes que aportaron asistencia técnica. Se capacitó a los empleados que cumplirían funciones de oficiales de microcréditos para que pudieran otorgar prés-

\footnotetext{
12 Véase Schor (1997)
} 
tamos individuales a microempresarios, utilizando la tecnología de microcréditos habitual: una evaluación cuidadosa de la capacidad de pago de los clientes, el otorgamiento de un crédito de corto plazo pagadero en cuotas, y una estrecha vigilancia de la disciplina de pago, seguidos de préstamos de más largo plazo o de mayor monto si el cliente resultaba ser confiable. Además, el donante ofrecía una línea de crédito, distribuida por un banco de segundo nivel, para financiar nuevos negocios. Sin embargo, esta línea de crédito no se otorgaba en condiciones concesionarias al banco prestador de primer nivel. La única ventaja de aceptarla era disponer de refinanciamiento a plazos algo mayores de los que podían obtenerse en el mercado financiero.

Hasta fines de 1996 cinco instituciones habían estado muy activas en el nuevo negocio: habían acumulado carteras de entre 0,5 y 6 millones de dólares y otorgado créditos por un promedio de 1.300 dólares con plazos medios de vencimiento de poco más de un año. Aunque el banco estatal era uno de esas cinco, tras dos años de iniciado el programa ya exhibía diferencias notables con las financieras privadas. El monto medio de los préstamos que había otorgado casi duplicaba el de dichas financieras (2.120 dólares en comparación con 1.000 dólares), el plazo de vencimiento era considerablemente más largo (22 meses en comparación con 12,5 meses) y la tasa de interés ascendía al 3,3\% mensual, siendo menor que la de la institución privada más barata $(4,8 \%)$ e inferior a la mitad de la que cobraba la financiera más cara $(6,8 \%$ mensual). ${ }^{13}$ Estas cifras parecen indicar que el banco estatal tenía menos interés en generar utilidades, aunque hasta ese momento ninguna de las cinco instituciones había alcanzado el punto de equilibrio. Sin embargo, se informó que las dos más grandes se estaban acercando a la zona de rentabilidad.

Al finalizar el programa, en la primavera de 2001, las cuatro financieras privadas participantes estaban a punto de ser rentables. Las dos más grandes habían creado carteras de créditos entre 8 y 12 millones de dólares ${ }^{14}$ lo que constituía una proporción significativa $(25 \%$ y $70 \%)$ del volumen total de su cartera y generaba una parte importante de los beneficios (entre $75 \%$ y $60 \%) .{ }^{15}$ Todas estas instituciones continuaron con el negocio de la microfinanciación, y en una de ellas los microcréditos constituyen la línea de negocios

\footnotetext{
13 Véase Schor (1997)

14 Véase Mommertz (2001), p. 8.

15 Información verbal obtenida del consultor encargado de asesorar el programa.
}

más importante, a tal punto que utiliza la siguiente consigna publicitaria: "La macrosolución para la microempresa". ${ }^{16} \mathrm{El}$ monto medio de los préstamos se mantuvo en 1.000 dólares a lo largo del tiempo y, por lo tanto, es indudable que estas instituciones prestan servicios a microclientes. La tasa de interés real para los préstamos en moneda local llega hasta $60 \%$ anual, una cifra bastante alta si se considera que la inflación en Paraguay es inferior al 10\%. No obstante, tasas asî no son inusuales en el país.

Lo antedicho es una prueba clara de que es posible crear departamentos de microcréditos en las instituciones financieras con fines de lucro de América Latina y lograr plena sostenibilidad financiera. Por ende, las instituciones seguirán en esta actividad después de que se hayan eliminado los subsidios otorgados para ingresar al mercado. El caso paraguayo, sin embargo, puede no ser representativo de toda América Latina. Paraguay no es el único país donde se han llevado a cabo experiencias de este tipo. De hecho, el Programa Microglobal se aplicó en varios países y sin duda Paraguay fue uno de los casos más exitosos y probablemente sea el mejor ejemplo de un auténtico proceso de downscaling en América Latina. ${ }^{17}$

\section{Europa oriental: el caso de Kazajstán}

Pasando a otro continente y echando una mirada a Europa oriental, una especie de campo de pruebas para la innovación institucional en las microfinanzas, la historia de los proyectos dirigidos a establecer actividades de microfinanciación en los bancos comerciales privados es en general mucho más breve, pero cabe esperar que se estén desarrollando proyectos tipo comparables a las experiencias realizadas en Paraguay. El Programa de Pequeñas Empresas de Kazajstán, puesto en marcha en 1998 con el apoyo del Banco Europeo de Reconstrucción y Desarrollo (BERD), puede ser un excelente ejemplo. ${ }^{18}$ Participaron siete bancos comerciales privados, o privatizados en 2001. Para fines de 2002, habían desarrollado una cartera de microcréditos de 73 millones de dólares. El promedio de los créditos otorgados es de 5.100 dólares y el saldo medio de las deudas asciende a 4.200 dólares. Estos valores son cuatro a cinco veces mayores que los del ejemplo paraguayo. No obstante, cabe aclarar que

\footnotetext{
16 Véase el sitio web www.vision.com.py.

17 Para más información, véase Wenner y Campos (1998).

18 Información recopilada durante una visita del programa. Fuente de los datos: www.ipcgmbh.com.
} 
el monto medio de los préstamos habituales en todos los proyectos de microcréditos de Europa oriental es considerablemente mayor que en los de América Latina. Todavía no se puede decir mucho de la rentabilidad de estos departamentos de microcréditos, ya que los subsidios para el desarrollo institucional aún no se han eliminado y las cifras sobre la contribución a los beneficios no han sido publicadas. Sin embargo, en las entrevistas personales con ejecutivos de los bancos participantes, éstos expresaron su compromiso de largo plazo con el negocio de la microfinanciación, ya que las perspectivas comerciales son buenas. Además, el banco comercial más importante de Kazajstán (Kazkommertsbank) no sólo es uno de los bancos participantes sino que también ha desarrollado una de las carteras de microcréditos más importantes (16,9 millones de dólares). Estos son indicios bastante confiables de que la microfinanciación perdurará cuando los organismos donantes las dejen.

Sin embargo, cabe señalar que en Kazajstán hay claros indicios de que los microcréditos, especialmente los de montos más bajos, no parecen ser considerados por los bancos como el negocio más atractivo para asignar sus recursos propios. En primer lugar, la mayoría de los bancos prefiere los préstamos individuales medianos y grandes, otorgados en el marco del Programa para la Pequeña Empresa. Incluso, algunos bancos querrían que se elevara el límite superior de los créditos otorgados en virtud de ese programa. Los donantes que aportan los fondos, en cambio, tienen especial interés en que el programa llegue a los microclientes más pequeños. En segundo lugar, generalmente los empleados que han sido capacitados como oficiales de créditos en el Programa para la Pequeña Empresa suelen ser ascendidos por los bancos a otras funciones de mayor responsabilidad. Pareciera que las microfinanzas se aprecian porque el programa ofrece capacitación y transferencia de conocimientos, que tienen valor en sí mismos, aunque el negocio de los microcréditos propiamente dicho sea menos atractivo que las transacciones con clientes más importantes. Lo más probable es que la sangría de recursos humanos no se detenga hasta que los recursos escasos destinados a microfinanciación permitan generar la misma rentabilidad que otras líneas de negocios. Esto puede ocurrir en el futuro cercano, porque el sector financiero de Kazajstán se caracteriza por un elevado nivel de competencia.
Es indudable que Kazajstán reúne todas las condiciones necesarias para que el enfoque basado en la incorporación de las microfinanzas en bancos se convierta en un éxito resonante. Sin embargo, al igual que en América Latina, no todos los proyectos de este tipo en Europa oriental están dando resultados igualmente buenos. Después de un comienzo relativamente lento, el de Ucrania parece tan promisorio como el de Kazajstán. El proyecto de Rusia, el más antiguo de Europa oriental, se inició en 1994 pero sufrió los graves embates de la crisis financiera rusa. Ésta no sólo afectó la calidad de la cartera de créditos, sino que llevó a la insolvencia a varios bancos participantes. Sólo quedó en pie uno de ellos, cuya estructura jurídica es la de una sociedad accionaria en la que el principal accionista es el gobierno y que, en consecuencia, no puede clasificarse como una verdadera institución con fines de lucro. Existen varios otros proyectos, como los de Armenia, Macedonia y Rumania, pero son demasiado recientes como para permitir un pronóstico, o son menos prometedores que el de Kazajstán.

Si bien la información presentada se reduce a dos ejemplos bastante exitosos, es posible extraer algunas conclusiones preliminares sobre las posibilidades de crear departamentos de microfinanciación en instituciones financieras con fines de lucro:

- Existen ejemplos exitosos, pero (todavía) son pocos.

- Esos ejemplos exitosos tienen en común las siguientes características:

- El mercado financiero en los dos países considerados es muy competitivo y las instituciones con fines de lucro existentes siempre están buscando nuevos negocios.

- El mercado financiero para microclientes no está bien cubierto por las instituciones sin fines de lucro existentes, que ofrecen el mismo producto pero que tienen la ventaja comparativa de ser, precisamente, sin fines de lucro.

En resumen, es posible realizar actividades de microfinanciación a través de las instituciones con fines de lucro, pero hasta ahora las experiencias exitosas no permiten inferir que se haya iniciado la era de la microfinanciación comercial. ${ }^{19}$

\footnotetext{
${ }^{19}$ Mommertz (2001) y Berger (2000) llegan a una conclusión similar.
} 


\section{IV}

\section{Creación de bancos de nuevo cuño: una solución intermedia entre las instituciones con y sin fines de lucro}

La muestra de bancos de nuevo cuño que se examina en este artículo abarca a los más importantes, pero ciertamente no al total de los que puedan haberse creado en el mundo. Todas las instituciones de microfinanciación mencionadas aquí pertenecen a una misma "red de microfinanzas", integrada por instituciones de donantes, una empresa de inversiones en microfinanciación, una empresa de consultoría especializada en financiamiento para el desarrollo y los propios microbancos. En esta muestra, la creación de bancos de nuevo cuño para la microfinanciación partió en los países en transición de Europa oriental. El primero fue el Banco para la Microempresa, en Bosnia y Herzegovina, que se creó en 1997. Muy poco después le siguió el Banco FEFAD, en Albania. Entretanto, la idea de los bancos de nuevo cuño se ha extendido a África, América Latina y Asia, aunque en estos continentes sólo existen una o dos de tales instituciones. A la fecha, la mayoría de los 15 bancos de nuevo cuño para la microfinanciación que se han creado se encuentran en Europa oriental.

Como desde el principio todas estas entidades contaban con una licencia formal para realizar actividades bancarias o financieras, la mayoría de ellas ya está ofreciendo (o al menos tiene proyectado ofrecer) servicios bancarios completos. Además de los préstamos a las microempresas y las pequeñas empresas y de los depósitos a plazos y de ahorro, tanto en moneda local como extranjera, estos bancos brindan servicios de pago y algunos también emiten cartas de crédito o cheques de viajero. Evidentemente, estos bancos no desean que sus microclientes transfieran sus operaciones a otros bancos formales cuando lleguen a ser empresas pequeñas o medianas. Por el contrario, su objetivo es convertirse en actores reconocidos en el mercado financiero local.

El criterio para crear esos bancos siempre fue similar. Se les confería la condición jurídica de sociedades accionarias y se obtenía de los organismos donantes el capital necesario para cumplir con las normas nacionales sobre requisitos mínimos de capital para fundar un banco.
En el cuadro 3 se ofrece una visión general de la estructura de propiedad de los bancos considerados y puede verse que los donantes que aparecen como accionistas de todos ellos son más o menos los mismos: el Instituto de Crédito para la Reconstrucción (Kfw); la Corporación Financiera Internacional (CFI) del Grupo del Banco Mundial; la Corporación Financiera Holandesa (FMO); la Fundación doen (Fundación Neerlandesa para el Desarrollo); y el Banco Europeo de Reconstrucción y Desarrollo (BERD). Al mismo tiempo, la comunidad de donantes tiene una participación mayoritaria en casi todos estos bancos.

El hecho de que los donantes tengan una participación mayoritaria permite extraer una conclusión importante: aunque estos bancos estén constituidos jurídicamente como empresas privadas y posean la estructura de gestión de sociedades accionarias, con administradores designados y un órgano de supervisión, no pueden considerarse "verdaderamente" privados. La estructura jurídica no es más que una herramienta que emplean los donantes para experimentar con innovaciones institucionales en la esfera del financiamiento para el desarrollo.

Sin embargo, el hecho de que la mayoría de los accionistas de estos bancos esté constituida por instituciones sin fines de lucro no significa una ausencia total de inversionistas privados. Uno de los accionistas es una institución financiera que actúa exclusivamente con fines de lucro. Se trata del Commerzbank, un importante banco comercial alemán. Curiosamente, éste ha invertido exclusivamente en bancos de Europa oriental, lo que puede indicar que las perspectivas comerciales de estos últimos los haga más interesantes para los inversionistas privados que una participación en un microbanco de Ghana o Haití.

Hay otro inversionista que aparece en todos los bancos incluidos en el cuadro 3: la IMI Ag. Esta es una compañía alemana de inversiones, que se especializa en la participación accionaria en microbancos. ${ }^{20} \mathrm{La}$

\footnotetext{
20 Véase: Die IMI Ag, http://www.imi-ag.de
} 
Mundo: Estructura de propiedad de los bancos de nuevo cuño (Porcentajes)

\begin{tabular}{|c|c|c|c|c|c|c|c|c|}
\hline & \multicolumn{5}{|c|}{$\begin{array}{c}\text { Instituciones de desarrollo } \\
\text { (sin fines de lucro) }\end{array}$} & \multirow{2}{*}{$\begin{array}{l}\text { Mixtas } \\
\text { IMI AG }\end{array}$} & \multirow{2}{*}{$\begin{array}{c}\text { Con fines } \\
\text { de lucro } \\
\text { Commerzbank }\end{array}$} & \multirow{2}{*}{$\begin{array}{c}\text { Otras } \\
\text { (con o sin } \\
\text { fines de lucro) }\end{array}$} \\
\hline & KfW & CFI & FMO & DOEN & BERD & & & \\
\hline \multicolumn{9}{|l|}{ Europa oriental } \\
\hline \multicolumn{9}{|l|}{ Banco de la Microempresa (MEB), } \\
\hline Bosnia y Herzegovina & 8 & 23 & 12 & - & 23 & 22 & 12 & \\
\hline Banco de Microfinanciación, Georgia & 20 & 16 & 10 & - & 10 & 29 & 15 & \\
\hline Banco de la Microempresa, Kosovo & 16 & 16 & 16 & - & 16 & 16 & 16 & \\
\hline Banco FEFAD, Albania & 25 & 20 & - & - & 20 & 15 & 20 & \\
\hline Caja de Crédito para la Microempresa, Moldova & - & 15 & - & 15 & 15 & 40 & - & 15 \\
\hline Banco de Microfinanciación, Serbia & 16 & 16 & 16 & - & 16 & 16 & 16 & \\
\hline Banco de Microfinanciación, Ucrania & 20 & 20 & - & 10 & 20 & 10 & - & 20 \\
\hline Banco ProCredit, Bulgaria & 20 & 20 & - & - & 20 & 20 & 20 & \\
\hline Banco MIRO, Rumania & 20 & 20 & 10 & - & 20 & 10 & 20 & \\
\hline \multicolumn{9}{|l|}{ América Latina } \\
\hline Microcrédito Nacional, Haití & - & 20 & 15 & - & - & 20 & - & 45 \\
\hline Sociedad Financiera Ecuatorial & - & - & - & 33 & - & 56 & - & 11 \\
\hline \multicolumn{9}{|l|}{ Resto del mundo } \\
\hline Nuevo Banco, Mozambique & - & 13 & 13 & 13 & - & 25 & - & 35 \\
\hline MEB, Filipinas & - & 10 & 10 & 20 & - & 20 & - & 40 \\
\hline Sikaman SLC, Ghana & - & 25 & 20 & 20 & - & 32 & - & 3 \\
\hline
\end{tabular}

Fuente: Internationale Micro Investitionen Aktiengesellschaft (IMI AG), www.imi-ag.de

mayor parte de sus inversiones se concentran en acciones de estos bancos de nuevo cuño, pero también tiene fondos invertidos en instituciones de microfinanciación creadas mediante la conversión de ONG en microbancos, como la Caja Los Andes de Bolivia y la Financiera Calpiá de El Salvador. La condición jurídica de la IMI AG es la de compañía privada, pero con toda razón se la considera una mezcla de empresa con fines de lucro y empresa sin fines de lucro. Si se analiza su estructura accionaria, se observa que es una copia casi exacta de la de los propios microbancos, ya que la mayoría accionaria está en manos de las mismas instituciones sin fines de lucro. La sociedad de inversiones Deutsche Investitions-und Entwicklungsgesellschaft (DEG), perteneciente a $\mathrm{Kfw}$ (una institución alemana para el desarrollo), posee el $14 \%$ de las acciones, la CFI el $16 \%$, la Fundación DOEN el 16\%, la FMO el 14,5\%, la Sociedad Belga de Inversiones para los Países en Desarrollo (BIO) el 7\% y ProCrédito, una fundación boliviana que realiza actividades de microfinanciación, el $6 \%$.

Sin embargo, existen dos inversionistas totalmente privados, a saber: IPC GmbH (19,5\%) e IPC Invest (7\%). El primero es una consultora privada, especializada en servicios de consultoría para las actividades de microfinanciación, mientras que el segundo es un instrumento de inversión de empleados de IPC $\mathrm{GmbH}$ que invirtieron allí sus propios ahorros. No hay duda de que se trata de un grupo muy especial de inversionistas privados: las inversiones son realizadas exclusivamente por personas físicas que al mismo tiempo obtienen sus ingresos de las actividades de consultoría en la esfera de la microfinanciación y que, además, participan en el proceso de desarrollo institucional de los microbancos, ya que su empleador, IPC GmbH, es contratado por los organismos donantes para que preste servicios de gestión a los microbancos durante la etapa inicial de desarrollo institucional (gráfico 1). Con estos inversionistas privados, que tienen una participación accionaria indirecta en los bancos de nuevo cuño a través de la IMI AG, se completa el panorama de la estructura institucional de estos bancos.

La estructura institucional, tanto del banco como la de la empresa de inversiones IMI AG, es realmente innovadora:

- Tras la fachada de empresa con fines de lucro hay una mezcla de inversionistas con y sin fines de lucro, la que puede ajustarse sin mucho esfuerzo a las perspectivas comerciales de cualquier institución de microfinanciación local o entidad de microfinanzas en general. Cuando la actividad microfinanciera no sólo logra cubrir los gastos, sino que también comienza a recuperar los cos- 
tos de oportunidad del capital, entonces el desempeño del microbanco es suficientemente bueno como para que se transforme en verdaderamente privado. En ese momento la estructura de los accionistas podría modificarse por la salida de los donantes a través de la venta de sus acciones a inversionistas privados. Del mismo modo, cuando las inversiones en las instituciones de microfinanciación se hayan vuelto realmente competitivas los donantes podrían salir de la IMI AG, que incluso puede convertirse en una empresa cuyas acciones se coticen en bolsa.

- La similitud en la estructura de propiedad de todos estos bancos de nuevo cuño garantiza el intercambio de información, la coordinación y, por lo tanto, el logro de economías de escala vinculadas con el control de las inversiones y la acumulación de conocimientos.

- Además, el que la empresa de consultoría IPC y sus empleados tengan una participación indirecta en la propiedad de los microbancos y a la vez trabajen para ellos -en el marco de un contrato de servicios de gestión- constituye una variante de un nuevo modelo de incentivos. Este modelo, denominado "consultoría a cambio de capital", ha surgido hace poco en los países industrializados occidentales. El concepto básico es brindar un incentivo a los consultores para que actúen en defensa de los intereses de los propietarios que emplean sus servicios de consultoría. Si el servicio da resultados positivos, los consultores participan del éxito, ya que el valor de sus acciones aumenta. Si los consultores no logran resolver el problema, su paquete accionario no les genera beneficios.

¿Cómo ha funcionado esta red institucional creada en los últimos cinco años en torno a la fundación de estos bancos de nuevo cuño?

En materia de cobertura ${ }^{21}$ y de orientación hacia los grupos destinatarios, el éxito de estos bancos es impresionante, como muestra el cuadro 4.

Por cierto, el monto medio de los préstamos otorgados en Europa oriental es considerablemente mayor que el que ofrecen, por ejemplo, las instituciones de América Latina. Esto refleja el diferente entorno de los países en transición y tal vez una diferente definición de los grupos a los que apuntan los bancos de Europa oriental, cuyo objetivo no es prestar servicios a los más pobres de los pobres. En todas las instituciones

21 Véase González-Vega (1998).

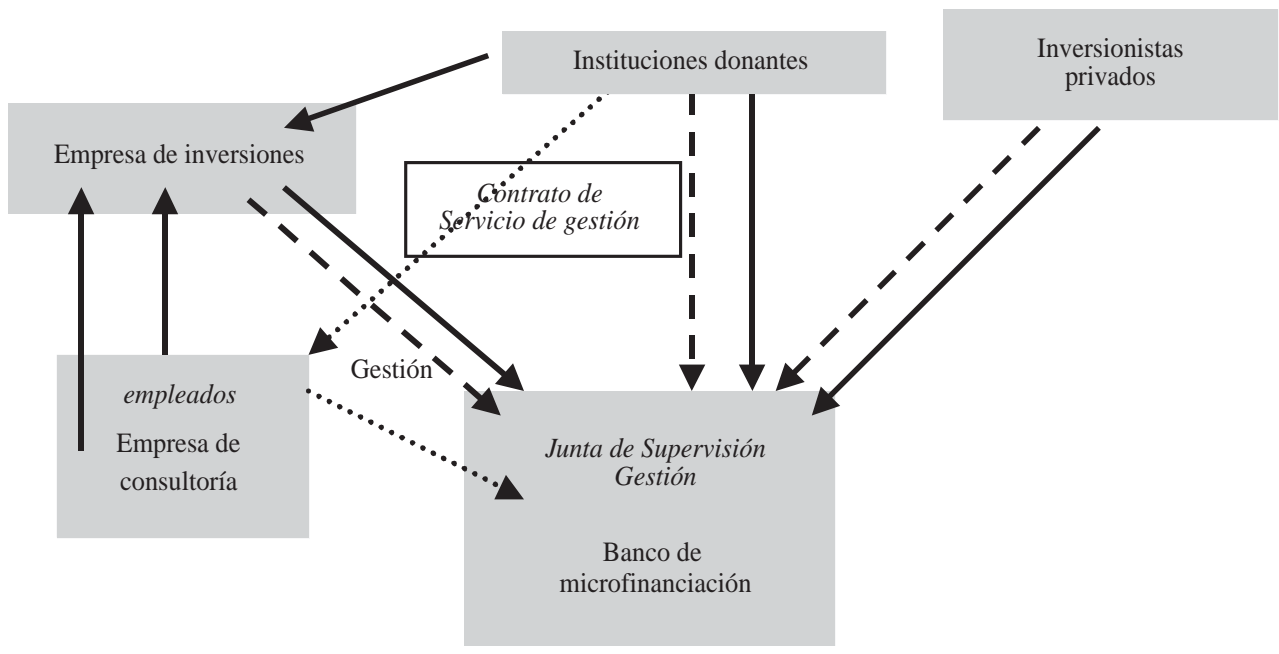

Fuente: Elaboración propia.

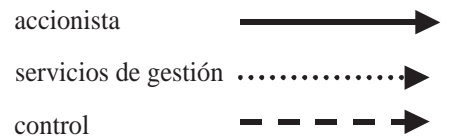




\begin{tabular}{|c|c|c|c|}
\hline Diciembre de 2002 & $\begin{array}{l}\text { Monto total de los } \\
\text { préstamos por pagar } \\
\text { (miles de euros) }\end{array}$ & $\begin{array}{l}\text { Monto medio de los } \\
\text { préstamos por pagar } \\
\text { (euros) }\end{array}$ & $\begin{array}{c}\text { Número de préstamos } \\
\text { por pagar }\end{array}$ \\
\hline MEB, Bosnia y Herzegovina & 33533 & 4513 & 7077 \\
\hline FEFAD, Albania & 29826 & 5227 & 5434 \\
\hline MBG, Georgia & 33098 & 1110 & 29815 \\
\hline MEB, Kosovo & 23731 & 5018 & 4504 \\
\hline MEC, Moldova & 3992 & 3593 & 1111 \\
\hline ProCredit, Bulgaria & 29317 & 5467 & 5107 \\
\hline MFB, Ucrania & 26055 & 4098 & 6056 \\
\hline MFB, Serbia & 40133 & 3844 & 9942 \\
\hline MIRO, Rumania & 10104 & 3900 & 2591 \\
\hline MCN, Haití & 2981 & 881 & 3383 \\
\hline SFE, Ecuador & 6746 & 1293 & 5217 \\
\hline Banco Nuevo, Mozambique & 1998 & 277 & 7212 \\
\hline MEB, Filipinas & 360 & 201 & 1794 \\
\hline Sikaman, Ghana & 282 & 552 & 487 \\
\hline \multicolumn{4}{|l|}{ Instituciones de referencia ${ }^{a}$} \\
\hline Caja Los Andes, Bolivia & 61272 & 1200 & 51073 \\
\hline Financiera Calpiá, El Salvador & 42717 & 954 & 44771 \\
\hline Financiera Confía, Nicaragua & 15023 & 736 & 20418 \\
\hline
\end{tabular}

Fuente: IMI AG.

a Aquellas instituciones que ya habían pasado por un proceso de conversión de onG a microbancos (upscaling).

consideradas la tasa de morosidad es muy baja (gráfico 2), lo que concuerda con una moderada proporción de deudas incobrables. Pero ' $¿$ se tradujo en ganancias la elevada tasa de reembolso?' (Morduch, 1999, p. 1571).

El cuadro 5, que examina la rentabilidad del capital lograda por los bancos de nuevo cuño, puede dar una primera impresión al respecto, aunque no del todo objetiva.

En sus estados contables oficiales, cuya auditoría estuvo a cargo de empresas especializadas externas, la gran mayoría de las instituciones de microfinanciación creadas hace más de dos años informa haber obtenido beneficios. Evidentemente, y para desgracia de los estudiosos interesados en contar con cifras sobre el éxito de este enfoque de desarrollo institucional, los datos contables oficiales no indican en qué grado esas instituciones todavía necesitan de subsidios. Es posible que aún los haya, ya sea con carácter de asistencia técnica pagada por los donantes (tales pagos por servicios de gestión ni siquiera aparecerían en la contabilidad de la institución) o en la forma de préstamos en condiciones concesionarias. Para lograr una imagen más realista sería necesario contar con datos de cuenta corregidos a fin de incluir los subsidios - datos que no están disponibles públicamente. Sin embargo, la información siguiente permitiría una primera aproximación:

- Al cabo de dos o tres años, los bancos deberían estar en condiciones de cubrir los costos administrativos, incluidos los salarios de los administradores. Todos los bancos que habían iniciado sus operaciones dos o tres años antes, e incluso algunos de iniciación más reciente, habían logrado cumplir con esta meta.

- Los subsidios necesarios para crear un banco de nuevo cuño -incluidas una casa central y una o dos sucursales - y para que éste alcance la sostenibilidad, en el sentido de cubrir todos los gastos, ascienden en promedio a entre 1,5 y 2 millones de euros. Naturalmente, la cifra depende del tamaño del banco.

- Tres de los microbancos (el Banco FEFAD de Albania, el Banco de la Microempresa de Bosnia y Herzegovina y el Banco de la Microempresa de Kosovo) ya han dejado de recibir subsidios directos. Los préstamos en condiciones concesionales sólo inciden en los resultados del banco de Bosnia y Herzegovina.

Dos o tres de estos bancos, por lo tanto, aparecen como rentables aunque sólo existen desde hace muy poco tiempo. No obstante, no parece que la 
GRAFICO 2

Bancos de nuevo cuño: Préstamos en mora, diciembre de 2002 (Porcentajes)

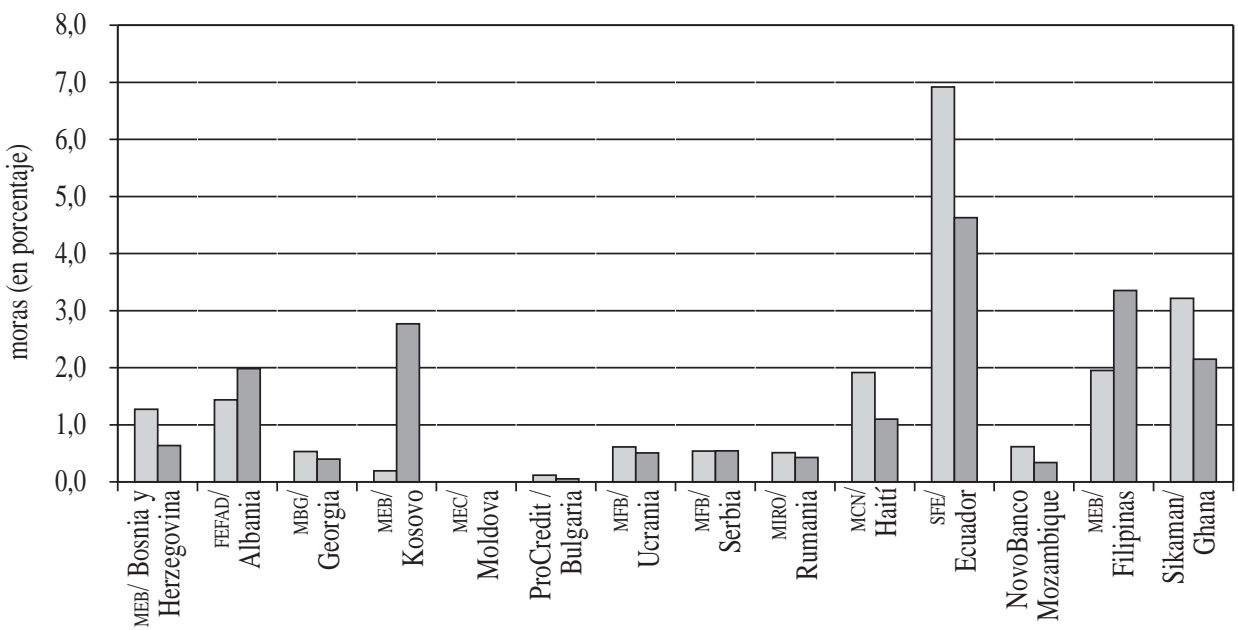

Número de morosos (30 días) $\square$ Volumen de morosos (30 días)

Fuente: IMI AG.

CUADRO 5

Mundo: Rentabilidad de los bancos de nuevo tipo

\begin{tabular}{|c|c|c|c|c|}
\hline Diciembre de 2002 & $\begin{array}{c}\text { Año de } \\
\text { fundación }\end{array}$ & $\begin{array}{c}\text { Rentabilidad } \\
\text { del capital } \\
\text { (porcentajes) }\end{array}$ & $\begin{array}{l}\text { Capital } \\
\text { (millones } \\
\text { de euros) }\end{array}$ & $\begin{array}{c}\text { Beneficios } \\
\text { (millones de } \\
\text { euros) }\end{array}$ \\
\hline
\end{tabular}

Europa oriental

Banco de la Microempresa (BEM), Bosnia y Herzegovina

Banco de Microfinanzas, Georgia

Banco de la Microempresa, Kosovo

1997

1999

1999

1999

2000

Caja de Crédito para la Microempresa, Moldova

Banco de Microfinanzas, Serbia

Banco de Microfinanzas, Ucrania

Banco ProCredit, Bulgaria

Banco MIRO, Rumania

América Latina

Microcrédito Nacional, Haití

Sociedad Financiera Ecuatorial

Resto del mundo

Banco Nuevo, Mozambique

Banco de la Microempresa, Filipinas

Sikaman SLC, Ghana

Instituciones de referencia utilizadas ${ }^{\mathrm{a}}$

Financiera Calpiá, El Salvador

Financiera Confía, Nicaragua

Caja Los Andes, Bolivia
2001

2001

2001

2002

2000

2001

2000

2001

2002

1988

1990

1992
0,56

$-0,11$

3,71

1,05

$-0,35$

$-3,64$

$-0,19$

0,07

$-0,9$

1

$-9$

10

0,54

0,3

$-0,12$

$-0,22$

$-0,1$

1,21

0,54

1,3

Fuente: Internationale Micro Investitionen Aktiengesellschaft (IMI AG), www.imi-ag.de

a Aquellas instituciones que ya habían pasado por un proceso de conversión de ONG a microbancos (upscaling). 
rentabilidad del capital sea suficiente para cubrir los costos de oportunidad en que basaría sus cálculos un inversionista privado, teniendo en cuenta el riesgo-país. Además, no basta la rentabilidad del capital por sí sola para comparar cuán lucrativas son las inversiones. Para realizar una evaluación de la rentabilidad sobre la base de valores netos actuales debe tenerse en cuenta el costo total de las inversiones y el monto que puede invertirse a una determinada rentabilidad media. Sin embargo, los datos presentados sugieren que se han hecho avances en el desarrollo de instituciones de microfinanciación, iniciado por estructuras de propiedad y gestión inteligentes e innovadoras.

Sin embargo, no sería justo concluir que estas innovaciones institucionales han permitido acercarse mucho más a hacer realidad las potencialidades de la microfinanciación. En la sección siguiente se explica por qué.

\section{V}

\section{Conclusión y perspectivas}

Las innovaciones institucionales fueron características de la "industria de las microfinanzas" a fines de la década de 1990 y principios del nuevo milenio. El término "industria de las microfinanzas" fue elegida deliberadamente porque estas innovaciones sin duda fueron llevadas a cabo por la facción del movimiento de microfinanciación que considera que ésta es un instrumento para desarrollar los mercados financieros más que una herramienta de desarrollo para combatir la pobreza en forma directa. De allí que se utilice como principal indicador de éxito la duración y grado del subsidio necesario para alcanzar la sostenibilidad financiera, y no una medida de costo-beneficio del impacto sobre la pobreza por cada dólar gastado.

Si se aplicara este último criterio de medición podría suceder que instituciones que llegan a clientes mucho más pobres, logrando mejorar sus ingresos, fuesen mejor evaluadas que los bancos de nuevo cuño mencionados en párrafos anteriores, aunque las primeras siguieran dependiendo de subsidios (Morduch, 1999, pp. 1592 a 1595). No tiene mucho sentido efectuar aquí un análisis más a fondo de este punto porque - citando una vez más el artículo germinal de Morduch - 'lamentablemente, quienes formulan las políticas tienen poco en qué basarse más allá de un puñado de estudios de casos y... ejemplos teóricos a favor y en contra' (Morduch, 1999, p. 1595). En justicia, cabe señalar que ninguna de las fuentes analizadas en el presente artículo sostiene que su misión sea prestar servicios a los más pobres entre los pobres, aunque algunos de sus clientes sean integrantes de este segmento de la población. El concepto de la microfinanciación con fines de lucro, así como la fundación de bancos de nuevo cuño, tiene por objeto desarrollar el mercado finan- ciero llegando a aquellos clientes a quienes no se había llegado antes, pero no de abajo hacia arriba sino de arriba hacia abajo. Teniendo en cuenta esta meta de desarrollo, el tiempo y el dinero invertidos para lograr la sostenibilidad financiera parece ser una medida pragmática pero aceptable.

Utilizando esta medida - aunque como estimación muy grosera ya que la información es insuficiente- hay casos notables de desempeño bastante satisfactorio de algunos departamentos de microfinanzas creados en bancos existentes (downscaling) y de algunos bancos de nuevo cuño. No es posible descartar, sin embargo, que la mayor parte del éxito de estos últimos se deba a la situación económica especial de los países en transición en que se hallan. Y en cuanto a los primeros, el solo hecho de que haya pocos proyectos exitosos de ese tipo y que los donantes apoyen la creación de bancos de nuevo cuño de propiedad mixta, incluso en algunos países donde se apoya simultáneamente el downscaling, parece indicar que la microfinanciación como solución que beneficia a todos sigue estando muy alejada de la realidad. Por último, pero no por ello menos importante, cabe mencionar que el nuevo modelo institucional de esos bancos puede generar problemas institucionales también nuevos. Para referirnos a sólo algunos de ellos:

- El nuevo modelo de incentivos de "consultoría a cambio de capital", dirigido a alinear los intereses de los consultores y los donantes, ¿tiene a la vez la capacidad potencial de generar nuevos problemas de incentivos? (Sties, 2003)?

- ¿Cuál es el punto de salida óptimo para los donantes-propietarios de los bancos de nuevo cuño? ¿Y cómo se garantiza que esa salida se haga efectiva? 
¿Es posible que la fundación de bancos de nuevo cuño con una estructura de propiedad mixta constituya la futura barrera al ingreso de los bancos privados al negocio de la microfinanciación, con el efecto no deseado de que la creación de institu- ciones destinadas a desarrollar los mercados financieros contribuyan a distorsionarlos?

Se necesitará mucha más investigación para poder dar respuestas satisfactorias.

(Traducido del inglés)
Adams, D.W., D.H. Graham y J.D. von Pischke (1984): Undermining Rural Development with Cheap Credit, Boulder, Colorado, Westview Press.

Banerjee, A. (2002): The Uses of Economic Theory: Against a Purely Positive Interpretation of Theoretical Results, MIT Working paper 02-24, Cambridge, Massachusetts, The MIT Press.

Baydas, M.M., D.H. Graham y L. Valenzuela (1997): Commercial Banks in Microfinance: New Actors in the Microfinance World, Economics and Sociology Occasional Paper, $\mathrm{N}^{\circ} 2372$, Columbus, Ohio, The Ohio State University.

Berger, M. (2000): Microfinance: An emerging market within the emerging markets, en S. Sawers, D. Schydlowsky y D. Nickerson (comps.), Emerging Financial Markets in the Global Economy, Washington, D.C., American University.

González-Vega, C. (1998): Microfinance: Broader Achievements and New Challenges, Economics and Sociology Occasional Paper, $N^{\circ} 2518$, Columbus, Ohio, The Ohio State University.

Hulme, D. y P. Mosley (1996): Finance Against Poverty, vol. 1, Londres, Routledge.

(1998): Microenterprise finance: Is there a conflict between growth and poverty alleviation?, World Development, vol. 26, $\mathrm{N}^{\circ}$ 5, Oxford, Reino Unido, Pergamon Press, mayo.

Khandker, S.R., H.A. Samad y Z.H. Khan (1998): Income and employment effects of micro-credit programmes: village-level evidence from Bangladesh, Journal of Development Studies, vol. 35, No 2, Londres, Frank Cass Publishers, diciembre.
Krahnen, J.-P. y R.H. Schmidt (1994): Development Finance as Institution Building, Boulder, Colorado, Westview Press.

Mommertz, R. (2001): Micro Global en Paraguay, Internal Working Paper, Frankfurt, IPC GmbH.

Morduch, J. (1999): The microfinance promise, Journal of Economic Literature, vol. 37, $\mathrm{N}^{\circ}$ 4, Nashville, Tennessee, American Economic Association.

(2000): The microfinance schism, World Development, vol. 28, No 4, Oxford, Reino Unido, Pergamon Press.

Rhyne, E. H. (2001): Mainstreaming Microfinance: How Lending to the Poor Began, Grew and Came of Age in Bolivia, Bloomfield, Connecticut.

Schor, G. (1997): Commercial Financial Institutions as Micro-Lending Partners. Some Lessons of the Micro Global Program in Paraguay, IPC Working Paper, Frankfurt.

Sties, A. (2003): Ownership Structure and Corporate Governance: Consulting for Equity in Development Finance Projects, Universidad de Heidelberg, inédito.

Vogel, R. (1984): The effect of subsidized agricultural credit on income distribution in Costa Rica, en D.W. Adams, D.H. Graham y J.D. von Pischke, Undermining Rural Development with Cheap Credit, Boulder, Colorado, Westview Press.

Wenner, M.D. y S. Campos (1998): Lecciones en la penetración de la banca comercial en microfinanzas: El caso de Banco de la Empresa, S.A., IDB Working Paper, Washington, D.C., Banco Interamericano de Desarrollo (BID). 
